㐘

\title{
A EXPERIÊNCIA DO CORPO E A CIRCUAMBULAÇÃO EM LUGARES SAGRADOS
}

\section{- OTÁVIO JOSÉ LEMOS COSTA ${ }^{1}$}

Pós-Doutorado na Universidade do Estado do Rio de Janeiro. Doutor em Geografia pela Universidade Federal do Rio de Janeiro - UFRJ. Mestre em Geografia pela Universidade Estadual do Ceará - UECE. Atualmente é Professor Adjunto da Universidade Estadual do Ceará, lecionando no curso de graduação e no Programa de Pós-Graduação em Geografia da UECE. Coordenador do Laboratório de Estudos em Geografia Cultural - LEGEC. Desenvolve pesquisas na área de Geografia Cultural, especificamente voltado para as temáticas: espaço e religião, geografia e patrimônio, paisagem vernacular. E-mail: otavio.costa@uece.br

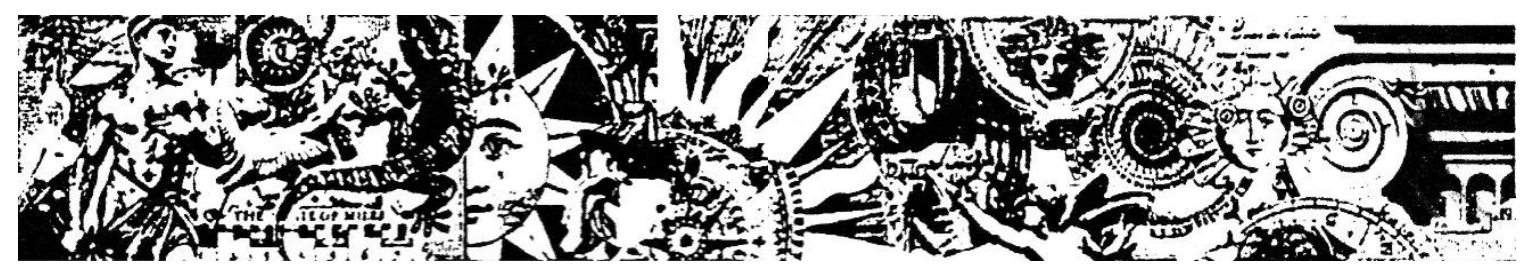

Resumo: 0 presente texto busca compreender como determinadas práticas rituais atreladas às formas simbólicas espaciais, promovem movimentos ou pequenos itinerários que sugerem mobilidades e que se tipificam pelo movimento de circuambulação em vários lugares sagrados. $O$ andar pelo espaço sagrado constitui um fluxo contínuo, idealizado por um movimento inconsequente e ao mesmo tempo consequente. Ao adentrar o lugar o sagrado, o fiel se apropriam deste lugar e por um sentimento de pertencimento idealiza seu lar. Evocam uma imagem de um passado mitificado. Movimentos estes que apresentam performances associadas à dimensão do corpo representado pelo movimento cíclico, determinando assim práticas ritualísticas. Assim, procuramos compreender como as práticas ritualísticas se inserem na lógica de micro itinerários simbólicos representados pela circuambulação e que se objetivam na construção de determinados lugares sagrados aqui representados por fiéis ou peregrinos que visitam santuários ou cidades sagradas.

Palavras-Chave: circuambulação; lugares sagrados; rituais; santuários. 


\title{
THE BODY EXPERIENCE AND CIRCUAMBULATION IN SACRED PLACES
}

\begin{abstract}
THE PRESENT TEXT AIMS TO UNDERSTAND HOW CERTAIN RITUAL PRACTICES LINKED TO THE SYMBOLIC SPATIAL FORMS, PROMOTE MOVEMENTS OR SMALL ITINERARIES THAT SUGGEST MOBILITIES AND THAT ARE TYPIFIED BY THE MOVEMENT OF CIRCUAMBULATION IN SEVERAL SACRED PLACES. MOVING THROUGH SACRED SPACE IS A CONTINUOUS FLOW, IDEALIZED BY AN INCONSEQUENT AND CONSEQUENT MOVEMENT. WHEN ENTERING THE PLACE THE SACRED, THE FAITHFUL TAKES OWNERSHIP OF THIS PLACE AND A SENSE OF BELONGING IDEALIZES THEIR HOME. THEY CONJURE UP AN IMAGE OF A MYTHIC PAST. MOVEMENTS THAT PRESENT PERFORMANCES ASSOCIATED TO THE DIMENSION OF THE BODY REPRESENTED BY THE CYCLIC MOVEMENT, THUS DETERMINING RITUALISTIC PRACTICES. THUS, WE TRY TO UNDERSTAND HOW THE RITUAL PRACTICES ARE INSERTED IN THE LOGIC OF MICRO-SYMBOLIC ITINERARIES REPRESENTED BY THE CIRCUAMBULATION AND THAT ARE OBJECTIFIED IN THE CONSTRUCTION OF CERTAIN SACRED PLACES REPRESENTED HERE BY FAITHFUL OR PILGRIMS WHO VISIT SACRED SHRINES OR CITIES.
\end{abstract}

KEYWORDS: CIRCUAMBULATION; SACRED PLACES; RITUALS, SHRINES.

\section{LA EXPERIENCIA CORPORAL Y LA CIRCUAMBULACIÓN EN LUGARES SAGRADOS}

RESUMEN: EL PRESENTE TEXTO BUSCA COMPRENDER COMO CIERTAS PRÁCTICAS RITUALES ASOCIADAS A LAS FORMAS SIMBÓLICAS ESPACIALES, PROMUEVEN MOVIMIENTOS O PEQUEÑOS ITINERARIOS QUE SUGIEREN MOVILIDADES Y QUE SE TIPIFICAN POR EL MOVIMIENTO DE CIRCULACIÓN EN VARIOS LUGARES SAGRADOS. EL ANDAR POR EL ESPACIO SAGRADO CONSTITUYE UN FLUJO CONTINUO, IDEADO POR UN MOVIMIENTO INCONSECUENTE Y AL MISMO TIEMPO CONSECUENTE. AL ADENTRAR EL LUGAR LO SAGRADO, EL FIEL SE APROPIA DE ESTE LUGAR Y POR UN SENTIMIENTO DE PERTENENCIA IDEALIZA SU HOGAR. EVOCAN UNA IMAGEN DE UN PASADO MITIFICADO. MOVIMIENTOS ESTOS QUE PRESENTAN PERFORMANCES ASOCIADAS A LA DIMENSIÓN DEL CUERPO REPRESENTADO POR EL MOVIMIENTO CÍCLICO, DETERMINANDO ASÍ PRÁCTICAS RITUALES. ASÍ, PROCURAMOS COMPRENDER CÓMO LAS PRÁCTICAS RITUALES SE INSERTA EN LA LÓGICA DE MICRO ITINERARIOS SIMBÓLICOS REPRESENTADOS POR LA CIRCULACIÓN Y QUE SE OBJETIVAN EN LA CONSTRUCCIÓN DE DETERMINADOS LUGARES SAGRADOS AQUII REPRESENTADOS POR FIELES O PEREGRINOS QUE VISITAN SANTUARIOS O CIUDADES SAGRADAS.

PALABRAS CLAVE: CIRCUAMBULACIÓN; LUGARES SAGRADOS; RITUALES; SANTUARIOS.

\section{Introdução}

A compreensão a respeito dos lugares sagrados estabelece uma ampla discussão dentro da geografia da religião. A relação entre o sagrado e os lugares se insere numa ordem pela qual a experiência religiosa engendra formas espaciais, reunindo um sistema de símbolos capaz de tornar os lugares em algo humanamente significativo. Essa experiência do sagrado, ao produzir na paisagem formas e funções religiosas, pode ser 
entendida através da explicação de Berque (1998) que propõe dois modos de compreensão da paisagem: como marca e matriz. Como marca, portanto, podemos compreender como a experiência religiosa é produzida no lugar e como matriz dessa experiência, surgindo nesse momento esquemas de percepção, de concepção e de ação, conferindo, portanto, uma identidade impressa na paisagem.

A existência de lugares sagrados, sobretudos aqueles criados a partir de uma hierofania, coloca o homem religioso em uma delimitação espacial. Eliade (1992) indica que não existe um espaço sagrado homogêneo, podendo haver rupturas, conferindo-lhe uma heterogeneidade estabelecida como uma experiência primordial que corresponde a uma fundação do mundo, não se tratando de especulação teórica, mas de uma experiência religiosa primária que precede a reflexão sobre o mundo. Portanto, o sagrado introduz uma ruptura entre o natural e o sobrenatural, mesmo que os seres sagrados sejam naturais como a água, o fogo, os animais. É sobrenatural a força ou a potência para realizar aquilo que os homens julgam impossível efetuar, contando com as forças e a capacidade humana. Este espaço, conforme explica Eliade (1992, p. 38), assume um caráter de duplicidade, ele ao mesmo tempo é centralizado e aberto. O espaço sagrado estabelece um centro no mundo, fixando um ponto de homogeneidade no espaço profano, providenciando ainda um lugar onde podemos habitar e estabelecer uma conexão com os deuses. Game (2001) nos chama atenção para as formas arquitetônicas e espaciais associadas às manifestações religiosas tais como colunas, cúpulas, templos, minaretes, entre outros. Estas formas evocam as imagens de abertura, conectando os homens ao divino, sugerindo ainda um sentido de pertencimento universal com um espaço cosmicizado.

A criação dos lugares sagrados também está associada à ação simbólica que o homem desenvolve através de processos que indicam a organização de um espaço socializado e que representa a própria história, estabelecendo um elo entre o mundo e as relações simbólicas. Neste sentido, concordamos com Rosendahl (2003, p. 203) ao reportar sobre a dimensão do lugar, afirmando que "o lugar simbólico não é meramente descoberto, fundado ou construído, mas operado e possuído pela comunidade religiosa”. Assim, o indivíduo ao vivenciar o lugar, estabelece uma relação de pertencimento, definindo realidades subjetivas que o definem através de um reconhecimento que parte das plurais dimensões significativas.

Entendemos que nos lugares sagrados existe um ordenamento de práticas organizado estruturalmente, através do qual um sistema social é transmitido, 
reproduzido e explorado. Assim, o tema do lugar, entendido na perspectiva simbólica do sagrado, aparece como um conceito cuja polissemia está ligada à própria existência do homem, quer seja individualmente ou em sua dimensão coletiva.

Os significados que os indivíduos atribuem aos lugares estão associados com o cotidiano, movimentos e atividades deles no lugar. Explorando o significado dos lugares na perspectiva do simbólico, especificamente na esfera do sagrado, pretendemos mostrar que não existe um único significado para o lugar, mas sim pluralidades interpretativas. Entendemos ainda que as relações intersubjetivas engendram a produção do lugar e esse universo plural de interpretações coaduna-se ao pensamento de Merleau-Ponty (1999, p. 328), que ao considerar o espaço como uma espécie de éter no qual todas as coisas mergulham, ou de concebê-lo abstratamente com um caráter que lhes seja comum, devemos pensá-lo como potência universal de suas conexões. Dessa forma, o mundo, enquanto lugar de vida não é apenas o ambiente real e lógico nas quais as coisas se tornam possíveis, mas um palimpsesto de experiências vividas e partilhadas em evidências de um mundo subjetivo.

O presente texto objetiva compreender como determinadas práticas rituais atreladas às formas simbólicas espaciais, promovem movimentos ou pequenos itinerários que sugerem mobilidades e que se tipificam pelo movimento de circuambulação em vários lugares sagrados. Movimentos estes que apresentam performances associadas à dimensão do corpo representado pelo movimento cíclico, determinando assim práticas ritualísticas. Neste sentido, conforme Bell (1997, p.3) “o estudo do ritual teve início com um debate prolongado e influente sobre as origens da religião que deram origem a vários estilos importantes de interpretação a partir do qual novos campos de bolsa de estudos surgiram”. Assim, procuramos compreender como as práticas ritualísticas se inserem na lógica de micro itinerários simbólicos representados pela circuambulação e que se objetivam na construção de determinados lugares sagrados.

\section{A circuambulação enquanto movimento do sagrado}

O vocábulo circuambulação geralmente não se encontra na maioria dos dicionários e está relacionado a determinados espaços sagrados ou práticas ritualísticas desenvolvidas por aqueles que frequentam lugares de culto ou adoração. O termo circum significa "em volta de", "em redor de" e ambulação, termo de origem latina, apresenta o sentido de passear, deslocar. Portanto, caminhar pelos espaços sagrados, adquire uma 
postura associada a dimensão do sagrado, no qual os itinerários simbólicos indicam uma conduta quase sempre circular. Caminhar pelo templo ou em torno de uma forma simbólica sagrada indica posturas que se conformam a ritos que são adotados em determinados lugares sagrados.

Algumas práticas rituais podem ser entendidas como circuambulação. Assim podemos falar do povo hebreu que ao dar voltas no tabernáculo (Salmo 26, versículo 6), realizava um ritual circuambulatório ou quando os adeptos do islamismo ao darem voltas em torno da Caaba em Meca também expressam um movimento simbólico. Os budistas ao fazerem o movimento circular em volta de uma Estupa que é um monumento construído com um formato de torre e geralmente cônico, sugerindo que se faça aí o movimento de circuambulação para idealizar a sua arquitetura cósmica. Ou por que não falar dos romeiros em Juazeiro do Norte, no Ceará, que realizam pequenos círculos em torno da estátua do Padre Cícero? Ou ainda quando fazem o passeio no Largo do Socorro, realizando uma confusa mobilidade, porém eivada de um simbolismo que ordena crenças e uma experiência mítica.

O movimento circuambulatório nos remete ainda ao flanar, que indica um desprendimento do movimento cotidiano em determinados momentos. $\mathrm{O}$ ato de flanar se contrapõe ao ritmo cartesiano da vida. Então, flanar seria o ato mais involuntário pelo simples prazer do exercício contemplativo do lugar. Baudelaire (2001), destaca a figura do flanêur que realiza com prazer os que vivem na cidade em suas lides cotidianas, construindo um processo de percepção e representação da realidade urbana.

Os fiéis que frequentam determinados lugares sagrados, buscam a atmosfera mística e são absolvidos por esta atmosfera através das sensações que o lugar oferece. Sonoridade, cores e movimentos conformam um conjunto de práticas sem que haja a necessidade de um esforço consciente. $\mathrm{O}$ andar pelo espaço sagrado constitui um fluxo contínuo, idealizado por um movimento inconsequente e ao mesmo tempo consequente. Ao adentrar o lugar o sagrado, o fiel se apropria deste lugar e por um sentimento de pertencimento idealiza seu lar. Evocam uma imagem de um passado mitificado. Portanto, ao entrar no lugar sagrado, ele retoma seu tempo adquirido (ELIADE, 1991). A dimensão oferecida pelo espaço sagrado estabelece um novo ritmo temporal e por mais que o movimento exaustivo e constante realizado pelo ato de peregrinação ou repetitivo na circuambulação possa oferecer, aqueles movimentos são realizados em atos de contemplação e adoração. 
$\mathrm{O}$ ato de flanar em um espaço sagrado significa, portanto, uma reconstrução de um tempo adquirido e segundo Eliade (1991, p. 29) "o homem conhece vários ritmos temporais, e não somente o tempo histórico, ou seja, seu próprio tempo, a contemporaneidade histórica”. Itinerários simbólicos em espaços sagrados funciona como um retorno a sua existência, percursos que são experimentados na dimensão do corpo e sua relação com a sacralidade que o rodeia. É no encontro do corpo com a atividade do sagrado que percebemos a dimensão de uma espacialidade, aqui compreendida pela afetividade ou pertencimento ao lugar sagrado. Uma afetividade que é compartilhada a partir da fé e representada pelo movimento que eleva a corporeidade inserida em possibilidades espaciais.

Fazer um movimento de circumambulação, em seu sentido amplo, nos lugares sagrados, é revelar aquele momento que fiel se revela para o sagrado. O sagrado se amplia pelo ato do movimento, fazendo renovar seu corpo e renovando também uma postura lúdica que através do ato repetitivo irá demonstrar uma lógica representacional do espaço. Aqui voltamos nossa compreensão para a dimensão sensível do corpo, ressaltando ser a tradição cartesiana algo que nos conduz a desprender-nos do objeto e ao tomar, portanto, uma atitude reflexiva que purifica simultaneamente a noção comum de corpo e de alma (MERLEAU-PONTY, 1999). Assim, o movimento empreendido pelo homem no lugar sagrado irá definir o corpo como sendo uma totalidade de partes sem interior, e uma alma como um ser inteiramente presente a si mesmo, sem distância.

Na dimensão ritualística da circuambulação em lugares sagrados, a atitude fenomenológica do corpo, nos sugere a dimensão do vivido, a percepção e o movimento que são atitudes complementares nas quais a experiência do corpo diante do sagrado carrega consigo todo um conhecimento sensível e que se expressa através dos gestos, das relações de pertencimento e palavras que articulam a trama do lugar sagrado.

Afirma Peirano (2000, p. 11) que "como sistemas culturalmente construídos de comunicação simbólica, os ritos deixam de ser apenas a ação que corresponde a um sistema de ideias, resultando que eles se tornam bons para pensar e bons para agir". Compreender, portanto, a ação ritualística, nos leva a pensar em um ordenamento do mundo no qual, o rito não é apenas um ato que se desenvolve espacialmente e temporalmente nos lugares sagrados. As relações que os indivíduos estabelecem com os outros lugares e que dão sentido à sua vida, dão origem a comportamentos relativos ao espaço que nenhuma análise funcional pode dar conta. (CLAVAL, 2001). 
Algumas singularidades dos lugares sagrados se manifestam a partir das formas simbólicas espaciais existentes, nas quais retratam uma estreita relação e que são mediatizadas por símbolos, podendo ser uma realidade material e unindo-se a uma ideia, a um valor ou a um sentimento. Entendemos, portanto, que as mediações simbólicas permeiam as atividades pessoais em relação aos lugares de afetividade e do pertencimento e aqui se revelam pelas práticas ritualísticas que se configuram pela circuambulação. Em seguida, apresentaremos através de três exemplos de lugares sagrados, como o fenômeno da circumambulação se manifesta em sua forma direta ou indiretamente no ato ritual de peregrinos em lugares sagrados.

\section{MECA: a circuambulação em torno da Caaba.}

Uma das peregrinações mais conhecidas do mundo é a realizada por fiéis muçulmanos à cidade de Meca. Conhecida como Hajj ou Hadj, essa é a denominação dado à peregrinação aquela cidade sagrada que é considerada como o último dos "cinco pilares sagrados da religião islâmica”. Sua visita, baseada em preceitos religiosos do Al Corão, deve ser obrigatória pelo menos uma vez na vida, para todo muçulmano adulto, desde que este disponha de condições financeiras e pleno estado de saúde. Afirma Sopher (1967, p. 51),

entre centros religiosos que também são moderadamente cidades, Meca e Medina são hoje quase únicos porque o seu papel religioso constitui a sua função urbana predominante. Eles são centros religiosos devido a sua associação com Maomé e o nascimento do Islã e Meca, também mantendo a sua sacralidade representada pela megalítica Kaaba

De acordo com a tradição da religião islâmica, a criação da cidade de Meca é resultado dos descendentes de Israel, primeiro filho de Abraão. A religião islâmica teve origem e ainda hoje está intimamente relacionada à cultura árabe (GAARDNER, 2000). Naquela época, Meca não era somente um polo comercial, mas também um dos lugares religiosos do Oriente Médio. Durante o século VII, a cidade funcionava como um grande centro comercial e, naquele mesmo período o profeta Maomé proclamou o Islã na região. Conforme Gaarder (op. cit), "as tribos nômades que viviam próximas à cidade já consideravam a pedra negra de Meca que recebia peregrinações bem antes da época de Maomé”. 
Situada geograficamente no Reino Hashemita do Hejaz, que foi um estado monárquico do Oriente Médio, a cidade de Meca conta com uma população de 1,7 milhões de habitantes, e se situa a $73 \mathrm{~km}$ de Jidá (cidade do litoral), em um vale estreito que fica 277 m acima do nível do mar (Figura 1). Para o Islã, é a região mais sagrada entre todas. Por isso, os adeptos da religião costumam fazer suas orações voltados para a direção à cidade de Meca. Todos os anos, aproximadamente 13 milhões de muçulmanos visitam o local, muitos deles para a realização do Hajj.

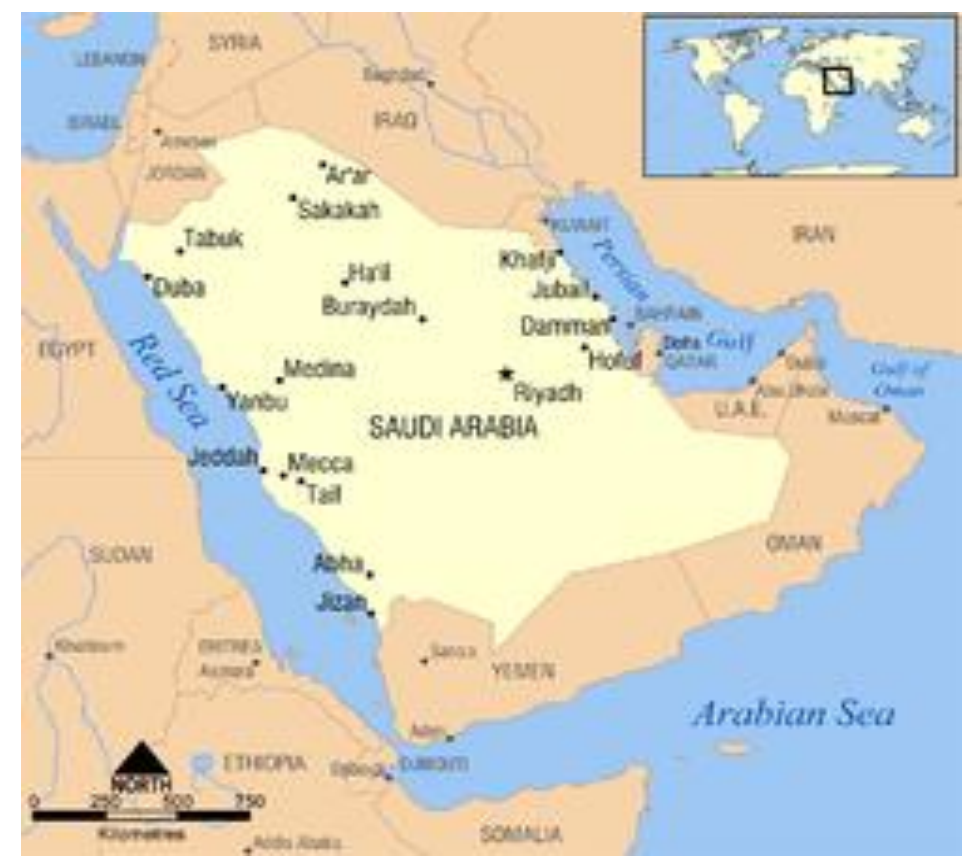

Figura 1: Localização da cidade de Meca na atual Arábia Saudita Fonte: Site Holy Makkah, 2018.

O Hajj é a maior peregrinação que ocorre na cidade de Meca, sendo realizada todos os anos. Ao menos uma vez ao ano, milhares de muçulmanos de vários países fazem uma visita à cidade com o objetivo de realizar a peregrinação. Eles ainda devem cuidar de seus dependentes e parente durante a realização da viagem. O Hajj deve ser feito pelo menos uma vez na vida do muçulmano.

No contexto ritualístico, o movimento de circumambulação representado pelos cíclicos movimentos que os peregrinos fazem em torno da Caaba, (Figura 2) representa um ato simbólico de adoração, ou seja, um ritual básico do Haji no Islam. A repetição cíclica deste ritual evoca a dimensão do sagrado e que segundo Berger (1985, p. 39) “o sagrado é apreendido como algo que salta para fora das rotinas normais do dia a dia, como algo de extraordinário e potencialmente perigoso, embora seus perigos possam ser domesticados e sua força aproveitada para as necessidades cotidianas”. Portanto, as 


\section{4:}

voltas que o peregrino realiza em torno da Caaba sugere um ato simbólico de adoração, penitenciando e ao mesmo demonstrando um sentido para sua vida. O peregrino circunda a Caaba como se fosse um corpo celestial orbitando um corpo maior. A circulação em torno da Caaba é para ser realizada no sentido contrário ao movimento do relógio, mostrando, dessa forma, que há um fator combinado entre o peregrino expressando sua fé suprema e uma prática ritualística que representa uma cosmologia envolvendo vários elementos entre os quais a performance nos quais seus participantes experimentam intensamente durante o movimento de circumambulação.

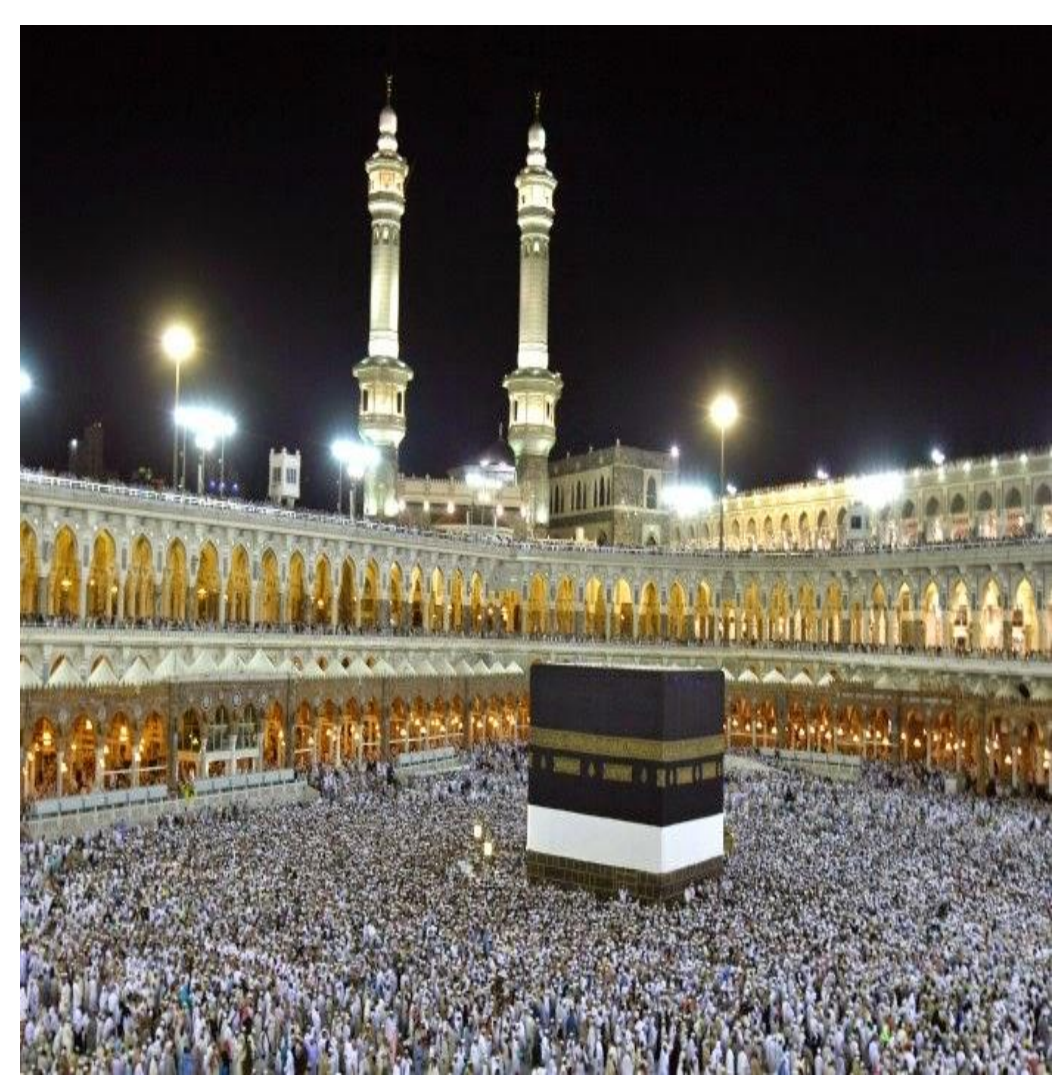

Figura 2: Movimento circuambulatório em torno da Caaba Fonte: Revista Pesquisa FAPESP, 2007.

\section{ESTUPA: o movimento circuambulatório budista}

A Estupa também conhecida como "chörten, chaitya ou pagode" (Cf. dicionário Aurélio, 1986) é um monumento construído para reverenciar os restos mortais de uma pessoa importante na religião budista. Apresenta a forma de uma torre, circundada por uma abóboda. São geralmente construídas em lugares com certo movimento de pessoas, tais como cruzamentos com o intuito de causas impacto onde foi construída. Desde os 
tempos pré-budistas, na Índia e em outros lugares, os restos mortais dos reis e heróis eram enterrados em túmulos. Inicialmente eram baixos montículos circulares de terra, mantidos no lugar por um anel de pedras. Estas pedras também serviam para demarcar aquele lugar sagrado (HARVEY, 1984).

A construção de uma estupa apresenta duas divisões: uma parte inferior e a própria estupa. A parte inferior, que vai até o princípio do domo é, na verdade, o trono sobre o qual a estupa está apoiada. A estupa inicia verdadeiramente a partir da coroa de folhas de lótus, juntamente dos quatro degraus, seguida da segunda coroa de lótus, o domo, e os elementos superiores. (Figura 3). De acordo com Usarski (2010), "incentivada pela crença, a peregrinação para uma estupa na qual ocorre a circumambulação, irá produzir meios espirituais pelos quais tranquilizam o coração, causam alegria e elevam a consciência do praticante.

O movimento circuambulatório diante das estupas budistas ocorre a partir da tradição na qual Buda o fez em volta da árvore de Bogh-Gaya. Na verdade, segundo Dortier (2010) ao nos apresentar uma definição do budismo, este irá afirmar que "o budismo é uma doutrinação moral e filosófica ligadas à prática de meditação. Não sendo uma religião propriamente dita, segundo aquele autor, uma vez que não há Deus, nem dogmas referentes ao além, nem revelações. Simbolicamente na doutrina budista, as estupas apresentam em sua estrutura o zócalo (a planta circular) como sendo um hemisfério que representa a terra, o hemisfério a abóboda celeste que indica a esplanada dos deuses e o mastro, a união da terra com o céu.

Enquanto prática ritual muito comum, a circuambulação diante das estupas, também conhecida como "kora", constitui em andar no sentido horário ao redor da estupa, sempre recitando mantras. Os peregrinos contornam as estupas sempre neste sentido, considerado na crença budista como o movimento do despertar (da inconsciência para a consciência).

A prática deste ritual nos remete a dimensão simbólica aqui representada por um itinerário e que segundo Parkin (1992, p. 22),

Muitos participantes em um ritual podem disputar e debater o significado e propriedade do comportamento ritual, usando palavras de grande efeito, ao fazer isso, eles só podem demonstrar a saliência, sucesso e eficácia do que eles têm a dizer através da prática performativa, e as questões de orientação espacial uma posição são os únicos meios à sua disposição, sendo fundamentalmente constitutivo do próprio ritual. 


\section{6:}

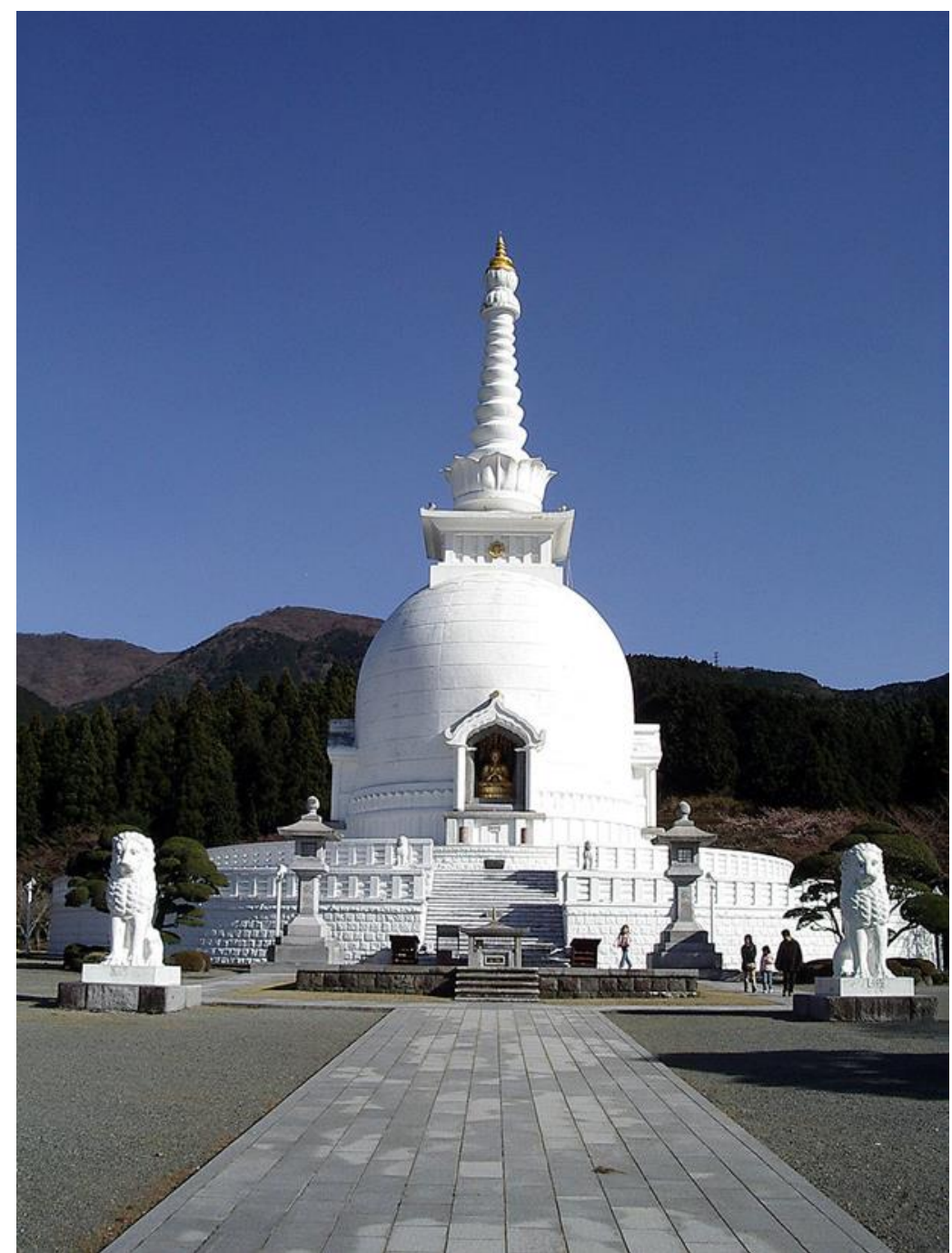

Figura 3: Estupa localizada em Gotemba, Shizuoka, Japan. Fonte: Wikipédia, $2018^{1}$.

Portanto, podemos perceber que prática ritual se estabelece numa consonância sócioespacial, pela qual o sujeito se insere em um conjunto de práticas sagradas. Se tratando da circuambulação budista em torno da "estupa", podemos verificar que as tradições, os costumes e as normas são realizadas em determinadas cerimônias através das quais o adepto do budismo, segundo Usarski (2010, p. 10) "direciona-se ao stupa considerando-o um objeto de contemplação, em que monumento passa a cumprir uma função devocional em prol do acúmulo de um karma salvificamente auspicioso realizado mediante a visita e a circuambulação" Assim, as práticas rituais ali realizadas conformam as tarefas de um cumprimento de atividades simbólicas atribuídos a uma forma simbólica especial que busca desempenhar a função sagrada e cerimonial.

\footnotetext{
${ }^{1}$ Wikipédia https://en.wikipedia.org/wiki/Stupa. Acessado em 2018 


\section{JUAZEIRO DO NORTE: identificando práticas circuambulatórias.}

Conhecida como a Meca do Cariri, apresenta a devoção do homem nordestino. A formação do espaço sagrado em Juazeiro teve início a partir da chegada de romeiros, atraídos pela mística de um sacerdote chamado Cícero Romão Batista, que chegou ao pequeno vilarejo em 1872. Esse lugar tinha apenas uma rua e algumas casas. A sua fundação está ligada á existência de três pés de juazeiro que metaforicamente consubstanciou-se em pedra e cal, transformando-se nas ruas e prédios da cidade, nos seus templos, nos seus lugares de adoração (CARVALHO, 1998).

O espaço sagrado em Juazeiro do Norte apresenta um conjunto de significados simbólicos que se individualizam. Um dos elementos geossimbolicos mais significativos na cidade de Juazeiro é a estátua do Padre Cícero, localizado em uma área periférica da cidade e denominada Colina do Horto. Construída em 1969, considerada uma das maiores do Brasil. Trata-se de uma imagem iconográfica bastante forte, pois de vários pontos do Vale do Cariri é possível visualizá-la. Passou a ser um ponto de visitação obrigatória do romeiro que vai ao Juazeiro do Norte. Outros espaços sagrados que compõem o roteiro devocional são: a Igreja de Nossa Senhora das Dores, a Capela do Socorro (local onde está o túmulo do Padre Cícero), a Casa dos Milagres e a Igreja dos Franciscanos, entre outros.

Localizado no mais antigo cemitério da cidade, o túmulo onde está sepultado o Padre Cícero é um dos locais mais visitados pelos romeiros ao estabelecer seu roteiro devocional. Segundo Carvalho (1998 p. 93), “é um espaço sagrado por excelência; importante que ele seja mantido em sua singeleza de adro e mausoléu, sobre cuja lápide de mármore os devotos colocam seus objetos para serem abençoados”. Importante ressaltar que esse espaço sagrado pode até representar uma morbidez para o turista religioso; entretanto, para o romeiro, está eivado de uma construção utópica que é vivida com imenso fervor. A Igreja Matriz de Nossa Senhora das Dores é outro espaço sagrado importante para devoto que vai a Juazeiro. Neste local são realizados os principais atos litúrgicos das romarias como a conhecida benção os romeiros ou "missa dos chapéus". É considerada um importante espaço sagrado, pois foi aí que ocorreu o milagre da hóstia, fato que deu início as romarias para a cidade.

É neste espaço cosmicizado, marcado por um forte catolicismo popular que milhares de romeiros de deslocam para Juazeiro do Norte para pagar suas promessas e estabelecer um conjunto de práticas rituais que envolvem a presença nos cultos 


\section{8:}

religiosos e a visitação aos lugares por eles considerados sagrados. A intensa movimentação no espaço urbano de Juazeiro configura, portanto, um movimento ambíguo marcado pela ordem-desordem que se configura em uma prática ritual. Desde o roteiro devocional, cuja ação é refletida na ação do corpo que se projeta na cidade sagrada, até movimentos singulares que configuram uma prática de circumambulação que pode ser exemplificada pelo movimento giratório em torno da estátua do Padre Cícero, localizada na serra do Horto (Figuras 4 e 5).

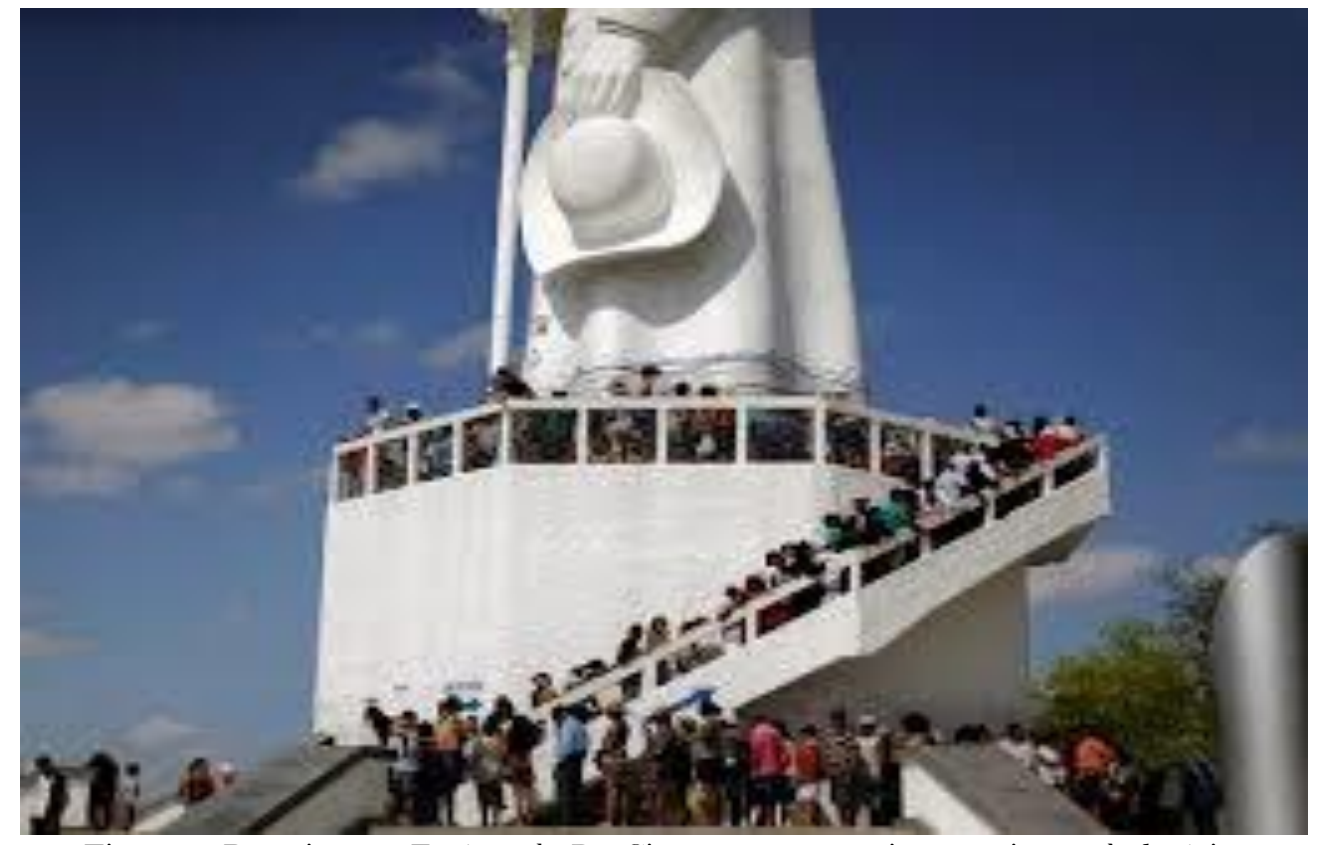

Figura 4: Romeiros na Estátua do Pe. Cicero em um movimento circuambulatório. Fonte: Costa, 2009.

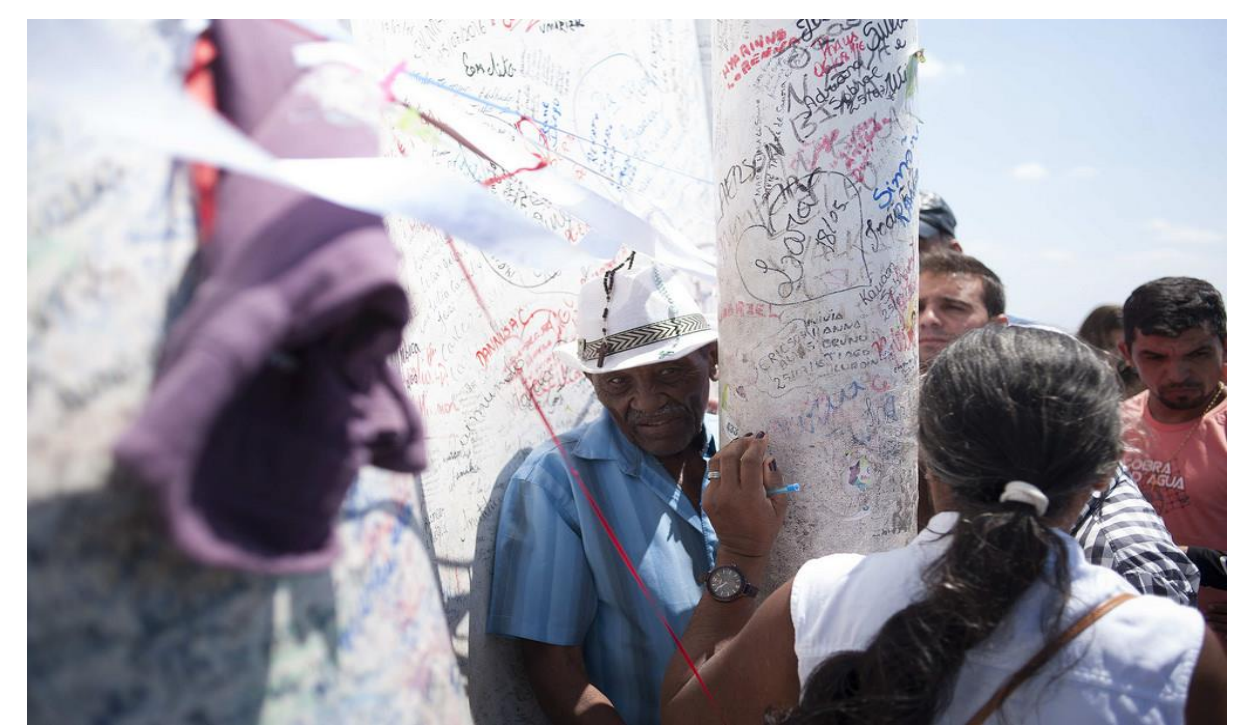

Figura 5: Romeiros em movimento circuambulatório em torno da estátua do Pe. Cícero Fonte: Reinaldo Canato, 2016. 
Dessa maneira, mesmo não tipificando um movimento tipicamente referenciado como circuambulação, podemos verificar que o ato de flanar pela cidade confere ao devoto/peregrino uma complexa intertextualidade pela qual o corpo adquire novos significados a partir de sua relação com as formas do sagrado aí existentes. O roteiro devocional constitui, portanto, uma volatilidade pela qual o urbano está impregnado de informações e segundo Araújo (2016, p. 37) "é constituído de uma volatilidade na sua estrutura concreta ou mesmo abstrata”. Podemos perceber que essa relação do corpo com o espaço, representado através de movimentos voláteis é uma evidência que se manifesta nas reinvindicações subjetivas de ser ou estar na cidade, conferindo, assim um espaço de pertencimento. $\mathrm{O}$ ato de girar em torno da estátua do Padre Cícero, por exemplo, anuncia uma articulação essencial entre o corpo e uma forma simbólica espacial. O romeiro se identifica pelo movimento, ou uma corpografia que consiste em uma performance do sagrado.

O movimento circuambulatório em uma cidade santuário como Juazeiro do Norte, apresenta um conjunto de relações nas quais são mediatizadas pelos símbolos e constituem, portanto, uma realidade material e une-se a uma ideia a um valor e a um sentimento. Para Entrikin (1991,) o conceito geográfico de lugar faz referências ao contexto de uma área que inclui objetos e ações. Neste contexto também estão presentes os elementos relacionados à natureza bem como aqueles representados pelas ações humanas. $\mathrm{O}$ interesse em descrever e compreender o contexto natural associado com as distintas formas de vida pode ser ampliado no sentido de envolver a dimensão simbólica estabelecida a partir das relações criadas entre o homem e seu meio.

\section{REFERÊNCIAS BIBLIOGRÁFICAS}

ARAÚJO, Marcos Allan Gonçalves de. Lugar, paisagem e religiosidade: moradores e romeiros no cotidiano do bairro do Socorro, Juazeiro do Norte-CE. Dissertação de Mestrado. Programa de PósGraduação em Geografia da UFPE, 2016

BELL, Catherine. Ritual. Perspectives and Dimensions. New York-Oxford:Oxford Univesity Press, 1997

BERGER, Peter. O Dossel Sagrado. Elemento para uma Teoria Sociológica da Religião. São Paulo: Paulus, 1985

BERQUE, A. Paisagem-Marca, Paisagem-Matriz. Elementos da problemática para uma Geografia da Religião. In: Correa, R.L. e Rosendahl, Z. (orgs.) Paisagem, Tempo e Cultura. Rio de Janeiro: EdUERJ, 1998. 
BAUDELAIRE, Charles. “O pintor da vida moderna." Sobre a modernidade. São Paulo: Paz e Terra, 2001

CARVALHO, Gilmar. Madeira e Matriz. Cultura e Memória. São Paulo: Annablume, 1998.

CLAVAL. Paul. A Geografia Cultural. Florinópolis. Editora da UFSc, 2001.

DORTIER, Jean-François. Dicionário de Ciências Humanas. São Paulo: Editora WMF Martins Fontes, 2010.

ELIADE, Mircea. Imagens e Símbolos: ensaios sobre o simbolismo mágico-religioso. São Paulo: Martins Fontes, 1991.

ELIADE, Mircea. O Sagrado e o Profano: a essência das religiões. São Paulo: Martins Fontes, 1992.

ENTRIKIN, J. Nicholas. The Betweeness of Place: towards a geography of modernity. London: Macmillan Education, 1991.

FERREIRA, Aurélio Buarque de Holanda. Novo Dicionário da Lingua Portuguesa. Rio de Janeiro: Nova Fronteira, 1986.

GAME, Ann. Belonging: Experience in Sacred Time and Space. In: MAY, J. e Thrift, N. Timespace of Temporality. London: Routledge: 2001.

GARDNER, Jostein. O Livro das Religiões. São Paulo: Companhia de Letras, 2000.

HARVEY, Peter. The symbolism of the early stupa. In: The Journal of the International Association of Buddhist Studies, vol 7, $\mathrm{n}^{\circ}$ 2, 1984. University of Wisconsin, Madison, USA

MERLEAU-PONTY, Maurice. Fenomenologia da Percepção. São Paulo: MartinsFontes, 1999 (texto original publicado em 1945)

PARKIN, David. Ritual as spatial direction and bodily division. In: COPPET, Daniel (org.) Understanding Rituals. London/New York: Routledge, 1992.

PEIRANO, Mariza. A análise antropológica de rituais. Série Antropológica. n. 270. Departamento de Antropologia, Unb, Brasília, 2000.

ROSENDAHL, Zeny. Espaço, Cultura e Religião: dimensões de análise. In: CORREA, Roberto Lobato, ROSENDHAL, Zeny (organizadores) Rio de Janeiro: Bertrand Brasil, 2003.

SOPHER, David. Geography of Religions. New Jersey: Prentice Hall, Inc., 1967.

USARSKI, Frank. Imaginários espaciais no budismo: reflexões sobre stupa em prol do diálogo entre a geografia da religião e a ciência da religião. Espaço e Cultura, UERJ, RJ, n. 28 P. 1-123, jul/dez de 2010. 